Check for updates

University of Manchester, UK

Louis.Appleby@manchester.ac.uk Follow Louis Appleby on Twitter @ProfLApple by

Cite this as: $B M J 2021 ; 372: n 834$ http://dx.doi.org/10.1136/bmj.n834 Published: 29 March 2021

\section{What has been the effect of covid-19 on suicide rates?}

\author{
Suicide rates haven't risen, but we should be cautious
}

Louis Appleby professor of psychiatry

Not a week passes without a story in the press about the impact of covid-19 on suicide. Claims on social media seem to appear daily. A year into the pandemic, what is the evidence? The short answer is that there has been little effect. But it's more complex than that, as it always is with suicide statistics.

Firstly, it's important to stress that the graphs and figures that are used to answer this question are not dry data. They represent real lives lost, real families devastated. No suicide rate, whether high or low, rising or falling, is acceptable. Even before covid-19, there were over 6000 deaths by suicide per year in the UK, an estimated 800000 worldwide. ${ }^{1}$

From the earliest days of the pandemic there was concern that suicide would increase. ${ }^{2}$ It wasn't hard to see where the risks might come from: anxiety about infection, isolation, disrupted care, domestic violence, alcohol, recession. Actual figures, though, took months to appear. Now we have reports from several countries, based on national or state level suicide data. They come from Australia, Canada, New Zealand, Norway, Peru, Sweden, and the US-high income countries in most cases-and they carry a consistent message. Suicide rates have not risen. ${ }^{3}$

In England we have had to set up new data collection because our coroner system is not quick enough for the close monitoring we need-the median time from death to inquest is 166 days. ${ }^{1}$ We now have "real time surveillance," recording deaths by suicide as they happen, providing figures for a population of around 9 million, one sixth of the country. Here, too, we have found no increase in the months post-lockdown. ${ }^{4}$ The same appears to be true of self-harm. ${ }^{5}$

Our conclusions at this stage, however, should be cautious. These are early findings and may change. Beneath the overall numbers there may be variations between demographic groups or geographical areas. After all, the impact of covid-19 has not been uniform across communities.

One country has reported a different pattern-Japan, where there has been a fall, then a rise, most marked in women and young people. ${ }^{6}$ The causes are uncertain, but economic factors and celebrity suicide may have played a part. Less clear is what this means for other countries: is Japan an outlier or warning to the rest of us? Then there is the report from Maryland in the US, where suicide overall has not risen, but ethnic differences are apparent-the rate rising in black populations, falling in white populations. In time, the question may be more nuanced-not whether suicide rates have risen in the pandemic, but in whom, when, and where. ${ }^{7}$

Yet the public narrative is dominated by alarming claims and predictions: suicide and self-harm are escalating. It is an epidemic, a tsunami-not only misleading, but potentially harmful to people who are already struggling. ${ }^{8}$ One notorious tweet claiming a "200\% rise" in suicide was reposted 31000 times before being taken down. ${ }^{9}$

How do we square the evidence on suicide with what surveys and calls to charities are telling us, that the pandemic has made our mental health worse? How can both be true? Perhaps as well as risks, there have been protections. We may have been more careful in lockdown to stay in touch, more alert to warning signs. In the face of a crisis, there may have been a greater sense of community, of getting through it together. Perhaps a belief too that it would soon be over, so that the distress that many felt did not become that most dangerous of moods, despair.

If so, we need to recognise the continuing risk as the pandemic enters its second year. The social coherence of last April seems to have eroded as we pit public health and business against each other and report our neighbours to the police. With each lockdown cycle people seem more weary and pessimistic. There are fears for children and the economy.

Recovery can be a dangerous time-as any clinician can tell you-as restrictions are lifted and we look at our lives in a new way. We need to ensure support for anyone lonely or mentally ill, in turmoil or financial hardship. We need to rediscover the values that unite us and the benefits of mutual support. We need to reassure ourselves that there is a way out of this crisis and a better, fairer, more compassionate society at the end of it.

If you're struggling, you're not alone. In the UK and Ireland, Samaritans can be contacted on 116123 or email jo@samaritans.org

Competing interests: LA chairs the national advisory group on suicide prevention at the Department of Health and Social Care. He receives funding from the Health Quality Improvement Partnership on behalf of UK governments.

Commissioned, not peer reviewed.

Office for National Statistics. Suicides in England and Wales: 2019 registrations. www.ons.gov.uk/peoplepopulationandcommunity/birthsdeathsandmarriages/deaths/bulletins/suicidesintheunitedkingdom/2019registrations.

2 Gunnell D, Appleby L, Arensman E, et alCOVID-19 Suicide Prevention Research Collaboration. Suicide risk and prevention during the COVID-19 pandemic. Lancet Psychiatry 2020;7:468-71. doi: 10.1016/S2215-0366(20)30171-1 pmid: 32330430

3 John A, Pirkis J, Gunnell D, Appleby L, Morrissey J. Trends in suicide during the covid-19 pandemic. BMJ2020;371:m4352. doi: 10.1136/bmj.m4352 pmid: 33184048

National Confidential Inquiry into Suicide and Safety in Mental Health. Suicide in England since the covid-19 pandemic: early figures from real time surveillance. https://documents.manchester.ac.uk/display.aspx?Do$\mathrm{ClD}=51861$. 
5 Kapur N, Clements C, Appleby L, et al. Effects of the COVID-19 pandemic on self-harm. Lancet Psychiatry 2021;8:e4. doi: 10.1016/S2215-0366(20)30528-9 pmid: 33308441

6 Tanaka T, Okamoto S. Increase in suicide following an initial decline during the covid-19 pandemic in Japan. Nat Hum Behav 2021;5:229-38. doi: 10.1038/s41562-020-01042-z pmid: 33452498

7 Bray MJC, Daneshvari NO, Radhakrishnan I, et al. Racial differences in statewide suicide mortality trends in Maryland during the coronavirus disease 2019 (covid-19) pandemic. JAMA Psychiatry 2020:e203938.pmid: 33325985

8 Hawton K, Marzano L, Fraser L, Hawley M, Harris-Skillman E, Lainez YX. Reporting on suicidal behaviour and COVID-19-need for caution. Lancet Psychiatry 2021;8:15-7.

doi: 10.1016/S2215-0366(20)30484-3 pmid: 33160581

9 Full Fact. There is no evidence that suicides have increased 200\% under lockdown. 29 June 2020. https://fullfact.org/online/suicide-200-percent.

This article is made freely available for use in accordance with BMJ's website terms and conditions for the duration of the covid-19 pandemic or until otherwise determined by BMJ. You may use, download and print the article for any lawful, non-commercial purpose (including text and data mining) provided that all copyright notices and trade marks are retained. 